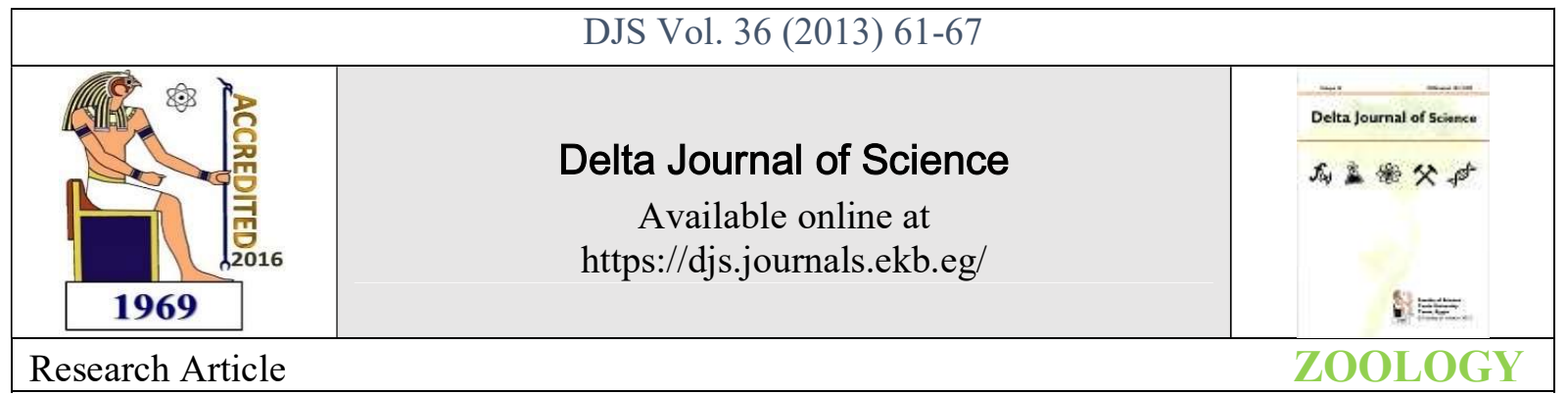

\title{
Detection of mutation in Exon 2-3 in Perforin gene and Exon4 in Fas gene in sample leukemia Iraqi patients
}

Najwa Shihab Ahmed $\{1\}$; Subhi Jawad Hamza $\{2\}$; Abdul Hussen Al-Faisal $\{3\}$; Wan Mohtar Yousaf $\{4\}$; Abdulameer M. Ghareeb $\{3\}$

$\{1\}$ Biotechnology Research Center, Al-Nahrain University, Baghdad, Iraq. \{2\} Baghdad

University, Science college, Biotechnology, $\{3\}$ engineering and biotechnology institute, Baghdad University, $\{4\}$ University Kebangsaan Malaysia, Faculty of Science and Technology,

School of Bioscience

\section{ABSTRACT}

This work aimed to study the possible mutations in Perforin gene (PRF1) exon 2-3 and Fas gene exon 4 in Acute Lymphocytic Leukemia (ALL) and Chronic Lymphocytic Leukemia (CLL) patients from Iraq. In an attempt to detect any mutation within PRF1 gene and Fas genes, a sequencing analysis for these genes were made. The results were alignment with sequences present in the Gene Bank seeking for homology and differences. A DNA sequence for Homo sapiens PRF1 gene was found compatible with genes of ALL, CLL patients and healthy controls, $100 \%$ compatibility was found in the flank DNA sense and antisense sequences from healthy. However, 99\% compatibility was detected for the genes isolated from ALL patients with an insertion of C697 and A698 G in the flank DNA sense strand and insertion of G697 and T698C in flank DNA antisense strand of the gene. Morever, 99\% compatibility was detected for the genes isolated from CLL patients with two transition mutations in the flank DNA sense strand of C957T and C1035T and one transition mutation in the flank DNA antisense strand of G957A. However, no mutations were detected in Fas gene isolated from ALL, CLL, and healthy controls.

\section{INTRODUCTION}

In humans, perforin deficiency leads to a potentially fatal disorder in infancy, familial hemophagocytic lymphohistiocytosis type 2 (FHLH2) (1). Patients with mutations in the perforin gene $(P R F 1)$ have absent or low perforin levels in NK cells and diminished lymphocyte cytotoxicity (2). Missense mutations in PRF1 have also been described in an adult with chronic active epstein barr virus (EBV) infection (3) and in children with bone marrow malignancies (4). The phenotypic expression of $P R F 1$ mutations is variable, and that the spectrum of perforin-related disease may include fatal immune dysregulation in early childhood; nonfatal, inflammatory reactions at any age and impaired tumour surveillance in children and adults. In other studies of FHLH2, over 50 mutations of the perforin gene (1 $\& 5$ ) have been identified, most of the perforin mutations in patients with FHLH2 do not lead to severe protein truncation but consist of amino acid substitutions and detection of mutant perforin by Western bloting of perforin lysates from individuals (6). Missense mutations in perforin, a critical effector of lymphocyte cytotoxicity, lead to a spectrum of diseases, from FHLH2 to an increased risk of tumorigenesis (1). Most missense PRF1 mutations in FHLH2 patients result in loss of function of perforin, most commonly due to unfolding and faulty trafficking of the protein $(7 \& 8)$, the mutation identified in perforin result in loss of a functional mRNA and complete loss of perforin protein or non functional protein $(9 \& 10)$. The present study aimed to investigate correlation between mutation in PRF1 and Fas gen and increasing leukemia in Iraqi population.

\section{Materials and methods}




\section{Collection of samples}

Five $\mathrm{ml}$ of blood was collected by vein puncture from 39 cases (21 ALL and $18 \mathrm{CLL}$ ) who were admitted to the National Center of Haematology/ Al Mustanisyria University. The disease was clinically diagnosed by the consultant medical staff at the centre. In addition, 5 apparently healthy controls (blood donors) were also included.

\section{Isolation of Lymphocyte}

Preparation of solutions and media were done according to the methods described by $\{11\}\{12\}$ unless mentioned. The lymphocytes were isolated from the heparinized whole blood using the method described by $\{13\}$ as follows: three $\mathrm{ml}$ of blood was centrifuged at $1000 \mathrm{rpm}$ for $15 \mathrm{~min}$. The plasma was collected for perforin estimation, buffy coat was collected in a $10 \mathrm{ml}$ centrifuge tubes and diluted with 5ml RPMI 1640 (cell suspension), five $\mathrm{ml}$ of the diluted cell suspension was layered on $3 \mathrm{ml}$ of ficoll-isopaque separation fluid, the tubes were centrifuged at $2000 \mathrm{rpm}$ for $30 \mathrm{~min}$ in a cooled centrifuge at $4^{\circ} \mathrm{C}$. After centrifugation, the mononuclear cells were visible as cloudy band between the RPMI1640 and lymphoprep layers. The band was collected in a $10 \mathrm{ml}$ test tube and the cells were suspended in $5 \mathrm{ml}$ RPMI 1640 . The tube was centrifuged at 2000rpm for $5 \mathrm{~min}$ (first wash), the supernatant was discarded and the cells were resuspended in $5 \mathrm{ml}$ RPMI 1640 (repeated twice). The suspension was centrifuged at $1000 \mathrm{rpm}$ for $10 \mathrm{~min}$, the supernatant was discarded. The precipitated cells were resuspended in $1 \mathrm{ml}$ RPMI solution and used in the planned experiments. Counting the cells were performed before experiment according to $\{13\}$, the numbers of lymphocytes were counted by light microscope and the cells concentration was adjusted to 1 X106 cell $/ \mathrm{ml}$. The isolated cells were grown in a flask containing $10 \mathrm{ml}$ RPMI 1640 medium supplemented with BSA and incubated at $37^{\circ} \mathrm{C}$ for $48 \mathrm{~h}$

\section{Isolation of Genomic DNA}

Genomic DNA was isolated from culture cells under aseptic condition according to the protocol described by promega company for wizard genomic DNA purification kit (Cat \#: A1120). Cells grown as liquid culture were harvested by centrifugation at $13000-16000 \mathrm{rpm}$ for $10 \mathrm{sec}$, the cell pellets were resuspended in PBS and vortex mixed. Nuclei lysis solution $600 \mu$ was added to cells grown as liquid culture and mixed by pipetting. RNase solution $3 \mu \mathrm{l}$ was added to the cell nuclei lysate and mixed, then incubated for $15-30 \mathrm{~min}$ at $37^{\circ} \mathrm{C}$ and then cooled to room temperature at $25^{\circ} \mathrm{C}$. Protein precipitation solution $200 \mu \mathrm{l}$ was added, vortex and chilled on ice for $5 \mathrm{~min}$, then centrifuged at $13000-16000 \mathrm{rpm}$ for $4 \mathrm{~min}$, supernatant was transferred to a tube containing $600 \mu \mathrm{l}$ isopropanol at room temperature, mixed by inversion and centrifuged at $13000-16000 \mathrm{rpm}$ for $1 \mathrm{~min}$. The supernatant was removed and the pellet was resuspended in $600 \mu$ of $70 \%$ ethanol and mixed well then centrifuged at $16000 \mathrm{rpm}$ for $1 \mathrm{~min}$. The ethanol a spirited and pellet was air-dried, the $100 \mu 1$ of DNA rehydration solution was added to dissolve the pellet.

\section{Detection of Perforin Gene and Fas Gene by Using PCR}

A 572 bp fragment containing exon 2-3 of PRF1 was amplified using a forward primer (5' ACGGCAGCATCTCTGCCGAA-3') and a reverse primer (5'GGGGTTGTTATTGTCCCACA-3') and 272bp fragment containing exon 4 of Fas was amplified using a forward primer (5'-AATCCATGCAGCTCCTGCC $\left.-3^{\prime}\right)$ and a reverse primer (5'- AGTCAGTGTTACTTCCCTAGGA 3') (Primers set supplied by first base Company, Malaysia). The PCR amplification was performed in a total volume of $25 \mu 1$ containing $2 \mu 1$ DNA (conc. $100 \mathrm{ng} / \mu \mathrm{l}$ ), $12.5 \mu \mathrm{l}$ Go Taq green master mix $2 \mathrm{X}$ (green maschuiter mix is a premixed ready to use solution containing Taq DNA polymerase, dNTPs, $\mathrm{MgCl} 2$ and reaction buffers at optimal concentrations for efficient amplification of DNA template by PCR supplied by promega (Promega corporation, USA), $1 \mu 1$ of each primer $(10$ $\mathrm{pmol} / \mu \mathrm{L})$ and up to $25 \mu 1$ with nucleases free water. The thermal cycling was as follows of PRF1 exon 2-3 gene: Denaturation at $95{ }^{\circ} \mathrm{C}$ for $4 \mathrm{~min}$, followed by 35 cycles of 94 ${ }^{\circ} \mathrm{C}$ for $40 \mathrm{sec}, 56^{\circ} \mathrm{C}$ for $30 \mathrm{sec}$, and $72{ }^{\circ} \mathrm{C}$ for $45 \mathrm{sec}$, with final incubation at $72{ }^{\circ} \mathrm{C}$ for $5 \mathrm{~min}$ [14] using a thermal Cycler. The thermal cycling was as follows of Fas exon 4 gene: Denaturation at $96{ }^{\circ} \mathrm{C}$ for $3 \mathrm{~min}$, followed by 35 cycles of 94 ${ }^{\circ} \mathrm{C}$ for $35 \mathrm{sec}, 63^{\circ} \mathrm{C}$ for $35 \mathrm{sec}$, and $72{ }^{\circ} \mathrm{C}$ for $35 \mathrm{sec}$, with final incubation at $72{ }^{\circ} \mathrm{C}$ for $5 \min [9]$ using a thermal Cycler. The PCR products were separated by $1.5 \%$ agarose gel electrophoresis and visualized by exposure to ultraviolet light $(302 \mathrm{~nm})$ after ethidium bromide staining.

\section{Sequencing and Sequence Alignment}

Sequencing of exon 2-3 of perforin gene and exon 4 of Fas gene were done by First base company/Malaysia for sequencing of products through used individual sense and antisense primer were used in each sequencing reactions. Homology searches were conducted between the sequence of standard gene BLAST program which is available at the national center biotechnology information (NCBI) online at (http:// www.ncbi.nlm.nih.gov) and using BioEdit program.

\section{Results and discussion}

\section{Amplification of Exon 2-3 Perforin Gene}

The genomic DNA from 39 patient were extracted using wizard genomic DNA promega, PRF1 gene from genomic DNA were amplified by using specific PCR primers for exon $2-3$, results shown in figure (1) indicated that a yield of single band of the desired product with a molecular weight about 572 bp for exon 2-3 gene was obtained.

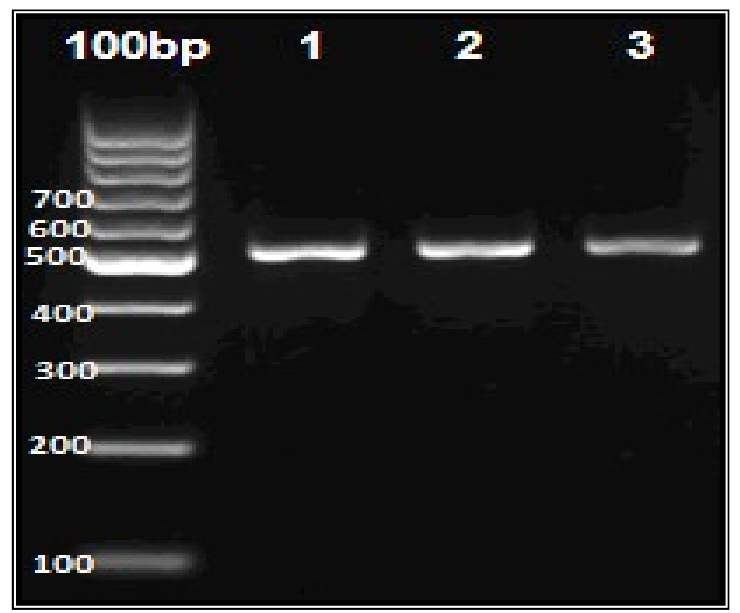

Figure (1) : Agarose gel electrophoresis for amplified PRF1 gene (Exon 2-3) of lymphocyte belonging to healthy, ALL, and CLL patients was done. Bands were fractionated by electrophoresis on a $1.5 \%$ agarose gel $(2 \mathrm{~h} ., 5 \mathrm{~V} / \mathrm{cm}, 1 \mathrm{X}$ Trisacetic buffer) and visualized under U.V. light after staining with ethidium bromide staining. Lane M:100bp ladder. Lane:1.(Healthy), Lane:2.(ALL), Lane:3.(CLL). 
Sequencing of coding regions of the amplified product (Exon 2-3) for these samples were done seeking for detection of any mutation within these sequence related to cancer development. Alignment of $P R F 1$ gene of all groups (Healthy, ALL, and CLL) with data published for known sequence seeking for enough homology. A homology with PRFl gene of Homo sapiens from the Gene Bank was done using the BioEdit software. $100 \%$ compatibility of that gene was found with $P R F 1$ gene (flank DNA sense and antisense of the gene) from healthy with standard $P R F 1$ of Gene Bank results as shown in figure (2).

\section{A: Sense of the partial PRF1 gene.}

Score $=750$ bits (406), Expect $=0.0$, Identities $=406 / 406$

Query 1 CAgTTCCATGTGgTACACACTCCCCCGCTGCACCCTGACTTCAagagGgCCCTCGgGGa 60 || || || || |||||||||||||||||||||||||||||||||||||||||||||||||||

Sbjct 672 CAGTTTCCATGTGGTACACACTCCCCCGCTGCACCCTGACTTCAAGAGGGCCCTCGGGGA 731

Query 61 CCTGCCCCACCACTTCAACGCCTCCACCCAGCCCGCCTACCTCAGGCTTATCTCCAACTA 120 ||||||||||||||||||||||||||||||||||||||||||||||||||||||||||| Sbjct 732 cCTGCCCCACCACTTCAACGCCTCCACCCAgCCCGCCTACCTCAgGCTAATCTCCAACTA 791

Query 121 CGGCACCCACTTCATCCGGGCTGTGGAGCTGGGTGGCCGCATATCGGCCCTCACTGCCCT 180

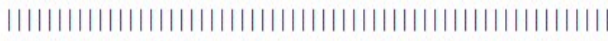
Sbjct 792 CGGCACCCACTICATCCGGGCTGIGGAGCTGGGIGGCCGCATATCGGCCCTCACTGCCCT 851

Query 181 GCGCACCTGCGAGCTGGCCCTGGAaGGGCTCACGGACAACGAGGTGGAGGACTGCCTGAC 240

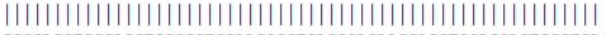
Sbjct 852 GCGCACCTGCGAGCTGGCCCTGGAaGGGCICACGGACAACGAGGIGGAGGACTGCCTGAC 911

Query 241 TGTCGAGGCCCAGGTCAACATAGGCATCCACGGCAGCATCTCTGCCGAagCCAAGGCCTG 300 |||||||||||||||||||||||||||||||||||||||||||||||||||||||||||| Sbjct 912 TGTCGAGGCCCAgGTCAACATAGGCATCCACGGCAGCATCTCTGCCGAagCCAAGGCCTG 971

Query 301 TGAGGAGAagaAgAagAaGCACAAGATGACGGCCTCCTTCCACCAAACCTACCGGGAGCG 360 ||||||||||||||||||||||||||||||||||||||||||||||||||||||||||||

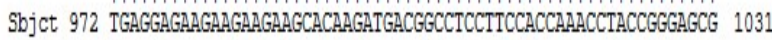

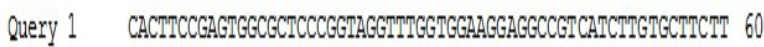
||||||||||||||||||||||||||||||||||||||||||||||||||||||||||||||||

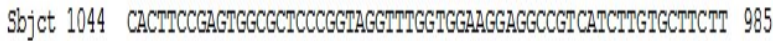

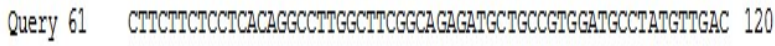

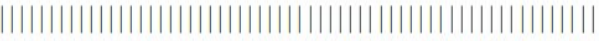

Sbjct 984 CMTCTMCTCCTCACAGGCCMIGGCTICGGCAGAGAIGCTGCCGIGGAMGCCTAMGITGAC 925

Query 121 CIGGGCTCGACAGICAGGCAGTCCTCCACCTCGITGTCCGIGAGCCCTICCAGGGCCAG 180

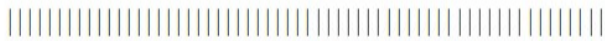

Sbjct 924 CIGGGCCTCGACAgICAGgCAgICCTCCACCTCGITGICCGIGAgCCCTICCAGGGCCAg 865

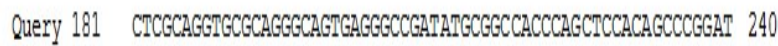

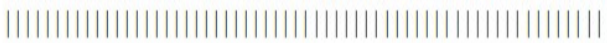

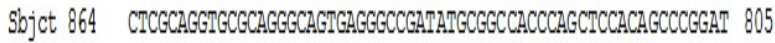

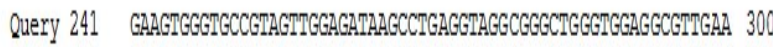

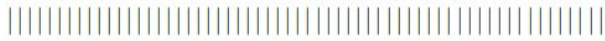

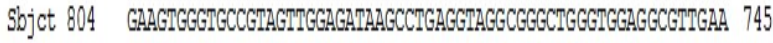

Query 301 GIGGIGGGGCAGGICCCCGAGGGCCCTCTIGAAGTCAGGGIGCAGCGGGGGAGIGIGIAC 360

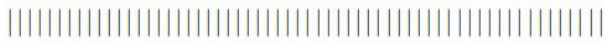

Sbjct 744 GIGGIGGGGCAGGICCCCGAGGGCCCTCTIGAAGICAGGGIGCAGCGGGGGAGIGMGIAC 685

Query 361 CACAIGgaACTG 373

| |||||||||| $\mid$

Sbjct 684 CACAIGGAaACTG 672
$(100 \%)$, Gaps $=0 / 406(0 \%)$, Strand=Plus/Plus

\section{B: Antisense of the partial PRF1 gene}

Score $=689$ bits (373), Expect $=0.0$,Identities $=373 / 373$ $(100 \%)$, Gaps $=0 / 373(0 \%)$

Strand=Plus/Minus

Figure (2): Sequencing of sense and antisense flanking the $P R F 1$ gene for healthy as compared with standard PRF1 obtained from Gene Bank (A: Sense of the gene; B: Antisense of the gene).

The PRF1 gene from ALL patients showed 99\% compatibility with standard $P R F 1$ of Gene Bank, and there was insertion of C 697 and A $698 \mathrm{G}$ in the flank DNA sense and insertion of G 697 and T698 C in flank DNA antisense strand leading to change all codons (framshift mutation). This can change amino acid and the effect could impair the function of perforin and cause problems in metabolic activity and effect function as shown in figure (3).

\section{A: Sense of the partial PRF1 gene.}

score $=750$ bits (406), Expect $=0.0$,Identities $=411 / 413$ $(99 \%)$, Gaps $=1 / 413(0 \%)$, Strand=Plus/Plus

Query 1 CTTCTCGCAGTTTCCATGIGGIACACACTCCCCCGCTGCACCCTGACTTCAagAGgGCCC 60

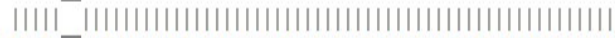
Sbjet 692 cTTCT-ACAgTTTCCATGIGgTACACACTCCCCCGCTGCACCCTGACTTCAagAGGGCCC 750

Query 61 TCGGGGaCCTGCCCCACCACTTCAACGCCTCCACCCAgCCCGCCTACCTCAGgCTTATCT 120 | | | | | | | | | | | | | | | | | | | | | | | | | | | | | | | | | | | | | | | | | | | | Sbjet 751 TCGGGGaCCTGCCCCACCACTTCAACGCCTCCACCCAgCCCGCCTACCTCAGgCTTATCT 810

Query 121 cCAaCTaCGGCACCCACTTCATCCGGGCTGIGGaGCTGGGIGGCCGCATATCGGCCCTCA 180

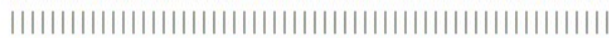

Sbjct 811 CCAACTACGGCACCCACTICATCCGGGCTGIGGAGCTGGGIGGCCGCATATCGGCCCTCA 870

Query 181 CTGCCCTGCGCACCTGCGAGCTGGCCCTGGAAGGGCTCACGGACAACGAGGTGGAGGACT 240 | | | | | | | | | | | | | | | | | | | | | | | | | | | | | | | | | | | | | | | | | | || |

Sbjet 871 CTGCCCTGCGCACCTGCGAGCTGGCCCTGGAaGGGCTCACGGACAACGAGGTGGAGGACT 930

Query 241 GCCTGACTGTCGAGGCCCAGGTCAACATAGGCATCCACGGCAGCATCTCTGCCGAaGCCA 300

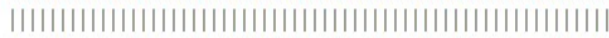

Sbjet 931 GCCTGACTGTCGAGGCCCAGgTCAACATAGGCATCCACGGCAGCATCTCTGCCGAaGCCA 990

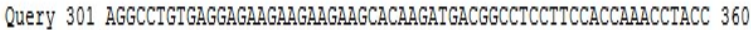
||||||||||||||||||||||||||||||||||||||||||||||||||||||||||||

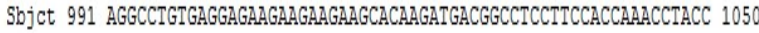

Query 361 GGgagCGCCACTCGgAagIGGTTGGCGGCCATCACACCTCCATTAaCGACCTG 413

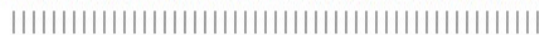

Sbjct 1051 GGGAGCGCCACTCGGAagTGGTTGGCGGCCATCACACCTCCATTAACGACCTG 1103

B: Antisense of the partial PRF1 gene. 
Score $=693$ bits $(375)$, Expect $=0.0$, Identities $=380 / 382$

$(99 \%)$, Gaps $=1 / 382(0 \%)$, Strand=Plus/Minus.

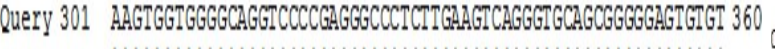 || || || || || || ||||||||||||||||||||||||||||||||||||||||||||||||||} Sbjct 772 AAGIGGIGGGGCAGGICCCGGGGGCCCTCTIGAaGICAGGGIGCLGCGGGGGAGTGGT 713013

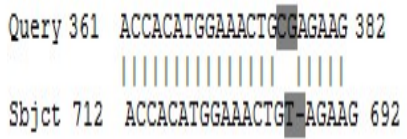

Query 1 CACTTCCGAGTGGCGCTCCCGGTAGGTTTGGTGGAAGGAGGCCGTCATCTTGTGCTTCTT 60 Sbjet 1044 CACTTCCGAGTGGCGCTCCCGGTAGGTTIGGTGGAAGGAGGCCGTCATCTTGTGCTTCTT 985 Query 61 CTTCTTCTCCTCACAGGCCTIGGCTTCAGCAGAGATGCTGCCGTGGATGCCTATGTTGAC 120 Sbjet 984 CTTCTTCTCCTCACAgGCCTTGGCTTCGgCAgagatgCTGCCGTGGATGCCTATGTTGAC 92

20 Query 121 CTGGGCCTCGACA GTCAGGCAGTCCTCCACCTCGTTGTCCGTGAGCCCTTCCAGGGCCAG 180

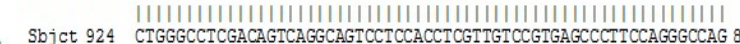

Query 181 CTCGCAGGTGCGCAGGGCAGTGAGGGCCGATATGCGGCCACCCAGCTCCACAGCCCGGAT 240 Sbjet 864 CTCGCAGGTGCGCAGGGCAGTGAGGGCCGATATGCGGCCACCCAGCTCCACAGCCCGGAT 805

Query 241 GAAGTGGGTGCCGTAGTTGGAGATAAGCCTGAGGTAGGCGGGCTGGGTGGAGGCGTTGAA 300 |||||||||||||||||||||||||||||||||||||||||||||||||||||||||||||||||||| sbjet 804 GAAGTGGGTGCCGTAGTTGGAGATAAGCCTGAGGTAGGCGGGCTGGGTGGAGGGTTGAA 745

Query 301 GTGGTGGGGCAGGTCCCCGAGGGCCCTCTTGAAGTCAGGGTGCAGCGGGGGAGTGTGIAC 360 |||||||||||||||||||||||||||||||||||||||||||||||||||||||||||||||||||| sbjet 744 GTGGTGGGGCAGGTCCCCGAGGGCCCTCTTGAAGTCAGGGTGCAGCGGGGGAGTGTGTAC 685

Query 361 CACATGGAAACTG 373 |l||||||||||| Sbjet 684 CACATGGAAACTG 672
Figure (3): Sequencing of sense and antisense flanking the PRF1 gene for ALL patient as compared with standard PRF1 obtained from Gene Bank (A: Sense of the gene; B: Antisense of the gene).

The PRF1 gene from CLL patients showed 99\% compatibility with standard $P R F 1$ of Gene Bank. There were two transition mutations in the flank DNA sense strand C957 $\mathrm{T}$ and $\mathrm{C} 1035 \mathrm{~T}$ while there are one transition mutation in the flank DNA antisense strand G $957 \mathrm{~A}$ as shown in figure (4); table (1).

\section{A: Sense of the partial PRF1 gene.}

Score $=739$ bits (400), Expect $=0.0$,Identities $=404 / 406$ $(99 \%)$, Gaps $=0 / 406(0 \%)$, Strand=Plus/Plus

Query 1 CAgTTTCCATGIGgTACACACTCCCCCGCTGCACCCTGACTICAagagGGCCCTCGGGga 60 | | | | | | | | | | | | | | | | | | | | | | | | | | | | | | | | | | | | | | | | | | || | Sbjet 672 CAgTTTCCATGTGGTACACACTCCCCCGCTGCACCCTGACTTCAAgAGGGCCCTCGgGGA 731

Query 61 сCTGCCCCACCACTTCAaCGCCTCCACCCAGCCCGCCTACCTCAgGCTAATCTCCAACTA 120

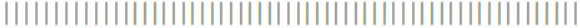

Sbjet 732 CCTGCCCCACCACTTCAaCgCCTCCACCCAGCCCGCCTACCTCAgGCTTATCTCCAaCTA 79

Query 121 CGGCACCCACTTCATCCGGGCTGTGGaGCTGGGTGGCCGCATAICGGCCCTCACTGCCCT 180

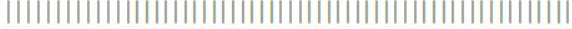
Sbjct 792 CGgCACCCACTTCATCCGGGCTGTGGaGCTGGGIGGCCGCATAICGGCCCTCACTGCCCT 851

Query 181 GCGCACCTGCGAGCTGGCCCTGGaAGGGCTCACGGACAACGAGGIGGaGgaCTGCCTGaC 240

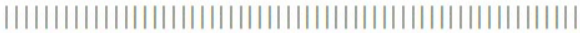
Sbjet 852 GCGCACCTGCGAGCTGGCCCTGGAaGGGCTCACGGACAACGAGGIGGAGGACTGCCTGAC 911

Query 241 TGICGAGGCCCAGgTCAaCATAGGCATCCACGGCAGCATCTCTGCIIGAagCCAAGgCCTg 300 | | | | | | | | | | | | | | | | | | | | | | | | | | | | | | | | | | | | | | | | | | | | | || | Sbjct 912 IGTCGAGGCCCAGGTCAaCATAGGCATCCACGGCAGCATCTCTGCC̈GAagCCAAGGCCTG 971

Query 301 TGaGGAGAagAagagGaAGCACAaGATGACGGCCICCTTCCACCAAACCTACCGGGAGCG 360

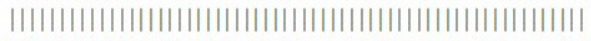

Sbjct 972 IGAGgAGAagAagaAgaAGCACAagaIGaCGGCCTCCTTCCACCAAaCCTACCGGGaGCG 1031

Query 361 CCAIITCGgaAgTGgTTGGCGGCCATCACACCTCCATTAaCGACCTG 406

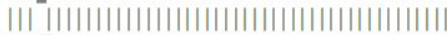

Sbjct 1032 cCAQTCGgAagIGGITGgCGgCCATCACACCTCCATTAaCGACCTG 1077

\begin{tabular}{|c|c|c|c|c|c|c|}
\hline & $\begin{array}{l}\text { location of } \\
\text { gene bank }\end{array}$ & $\begin{array}{l}\text { Nucleotide } \\
\text { change }\end{array}$ & $\begin{array}{l}\text { No. of codonl } \\
\text { location }\end{array}$ & Amino acid change & $\begin{array}{l}\text { Predicted } \\
\text { effect }\end{array}$ & $\begin{array}{l}\text { Typeof } \\
\text { mutration }\end{array}$ \\
\hline 1 & C957T & $C G A>T G A$ & 96/Sense & Argiginine 0 0pal & Notisense & Transition \\
\hline 2 & $\mathrm{Cl} 1035 \mathrm{~T}$ & CTC $>$ ITC & $122 /$ Sense & Leucine $>$ Phenylalanine & Missense & Transition \\
\hline 3 & G957A & $\mathrm{GGC} \mathrm{AGC}$ & 30/Antisense & Glysine $>$ Serine & Missense & Transition \\
\hline
\end{tabular}

\section{B: Antisense of the partial PRF1 gene.}

Score $=684$ bits (370), Expect $=0.0$,Identities $=372 / 373$ $(99 \%)$, Gaps $=0 / 373(0 \%)$, Strand=Plus/Minus

Figure (4): Sequencing of sense and antisense flanking the PRF1 gene for CLL patient as compared with standard PRF1 
obtained from Gene Bank (A: Sense of the gene; B: Antisense of the gene).

Table (1): Types of mutations detected in partial PRF1 gene of CLL patients.

Human perforin gene mutations were detected previously by several investigators. For instance, nine types of nonsense mutations and other four types of missense mutations were characterized in three cases from Japanese patients suffering from familial hemophagocytic lymphohistiocytosis FHLH2 (15). Also mutations in 12 base pair (codon 284-287) which are responsible for the change in four amino acids of the complex domain of a membrane protein were detected from Omani boy diagnosed at 44 days after birth suffering from FHLH2 disease (16) . Later, many mutations were detected in the PRF1 gene from eleven patients (six males and five females) during DNA sequencing of exon 2 and exon 3, of these mutations (17), seven different changes were identified in the coding region of the perforin gene, five of them $(265 \mathrm{C}>\mathrm{A}, 518 \mathrm{C}>\mathrm{T}, 363 \mathrm{C}>\mathrm{T}, 674 \mathrm{G}>\mathrm{C}$ and deletion $12 \mathrm{bp})$ are novel along with other ( 50 deletion $\mathrm{T}$ and $1122 \mathrm{G}>\mathrm{A}$ ). During this review, they recognized 40 mutations within coding region of $P R F 1$ gene in different ethics groups, but seven different mutations in the $P R F 1$ gene in Omanis determined clinically to have FHLH2 with a family history. (5) referred to perforin mutation identified in 7 of the 34 families FHLH2 of Turkey investigated, six children were homozygous for the mutations and one patient was a compound heterozygote, four novel mutation were detected (one nonsense, two missense, and one deletion of one amino acid). On the other hand, referred to a mutation in exon 2 (del207C) and exon 3(del 1090-91CT) were detected in FHLH2 patient from Japan lead to lower expression of perforin from lymphocyte of the patient (18). Also, one mutation in $A 91 V$ (C to $\mathrm{T}$ transition at position 272) in perforin gene was detected during a study on 30 cases of childhood acute lymphocytic leukemia (ALL) and $A 91 \mathrm{~V}$ frequency was significantly increased in childhood ALL but $A 91 \mathrm{~V}$ polymorphism was not associated with increased risk (19). Moreover, three heterozygous mutations were detected in a coding region of perforin gene in three patients of hemophagocytic lymphohistocytosis (14). While, 21 missense mutations in perforin gene of hemophagocytic lymphohistocytosis patients lead to absent or low levels of perforin in NK cells (20).

During a study on 60 cases familial hemophagocytic lymphohistiocytosis (FHLH2) 22 missense mutations were detected (P39H, G45E, V50M, D70Y, C73R, W95R, G149S, F157V, V183G, G220S, T221I, H222R, H222Q, I223D, $R 232 C, R 232 H, E 261 K, C 279 Y, R 299 C, D 313 \mathrm{~V}, R 361 \mathrm{~W}$ and $Q 481 P$ ) in perforin gene that lead to reduce or absence of perforin activity (8). Through their diagnosis of 9 Turkish patients suffering from FHLH2, a research group (1) identified five nonsense mutations $W 374 X$ and four different missense mutations namely $G 149 S, V 50 M, A 91 V$ and $A 523 D$. Other mutations were also detected by others investigator that reduced the functional activity and perforin expression such as $A 91 V$ mutation in NK and CD8+ cells (21) and frame shift mutation in perforin gene leading to stop codon which cause

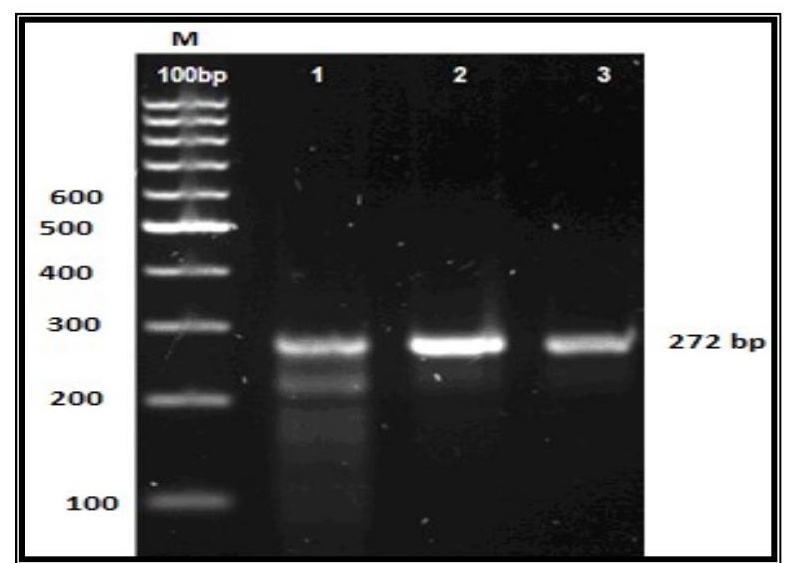

loss of perforin functional activity (10).

\section{Amplification and Sequencing of Partial Fas Genes}

Fas gene from genomic DNA were amplified by using specific PCR primers for exon 1, results shown in figure (5) indicated that a yield of single band of the desired product with a molecular weight about 272 bp for exon 1 gene was obtained.

Figure (5) : Agarose gel electrophoresis for amplified Fas gene (Exon 4) of lymphocyte belongs to healthy, ALL, and CLL patients. Bands were fractionated by electrophoresis on a $1.5 \%$ agarose gel $(2 \mathrm{~h} ., 5 \mathrm{~V} / \mathrm{cm}, 1 \mathrm{X}$ Tris-acetic buffer $)$ and visualized under U.V. light after staining with ethidium bromi

de Query 61 ggctTagaagiggaAmanactgcacccGgacccagamaccangigcagaigianacca 120

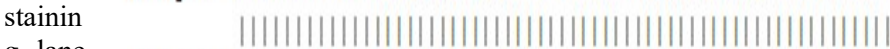

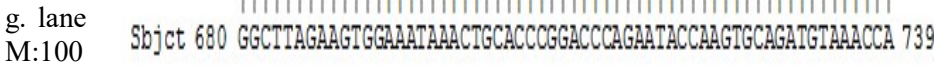
bp

ladder.

Lane: 1

.(Healt

hy),

\section{Query 121 AaCTTTTTTGTAACTCTACTGIATGIGAACACTGIGACCCTIGCACCAA 170

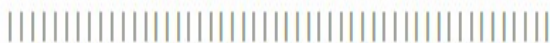
Sbjct 740 AACTTTTTTGTAACTCTACTGTATGTGAACACTGTGACCCTTGCACCAA 789 Lane:

2.(ALL), Lane:3.(CLL).

After alignment of Fas gene of the healthy, ALL and CLL groups with the Fas of Homo sapiens from the Gene Bank using the BioEdit software, we found that part of Fas gene (flank DNA sense and antisense of the gene) from healthy having $100 \%$ compatibility with standard Fas gene obtained from Gene Bank as shown in figure (6).

\section{Query 52 TTGGIGCAAGgGTCACAGTGTTCACATACAGIAGAGTTACAAAAAAGMTTGGTTAACAT 111

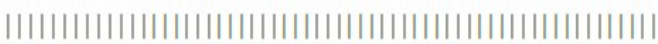 \\ Sbjct 789 TTGGTGCAagGgTCACAgTgTTCACATACAGIAgagTTACAAaAaAagTTTGGTTTACAT 730}

\section{Query 112 CTGCACTTGGTATTCTGGGICCGGGIGCAGTTATTTCCACTTCTAAGCC 161

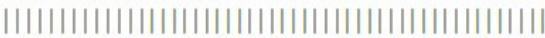 \\ Sbjct 729 CTGCACTIGGTATTCTGGgTCCGGGTGCAGTTTATTTCCACTTCTAAGCC 680}

\section{A: Sense of the partial Fas gene.}

Score $=204$ bits $(110)$, Expect $=2 e-50$, Identities $=110 / 110$ $(100 \%)$, Gaps $=0 / 110(0 \%)$, Strand=Plus/Minus.

\section{Query 61 gGctragaggiggananancigcacccGgacccaganaccangigcagangTanacca 120

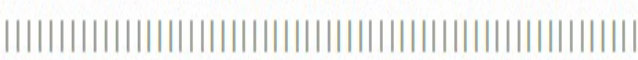

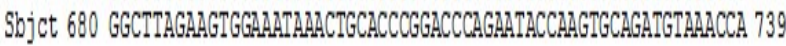

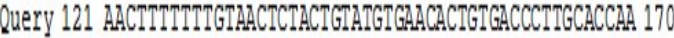 || ||||||||||||||||||||||||||||||||||||||||||||||||

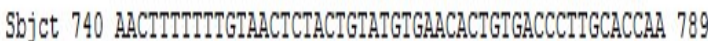

\section{B: Antisense of the partial Fas gene.}

Score $=204$ bits (110), Expect $=9 e-52$, Identities $=110 / 110$ $(100 \%)$, Gaps $=0 / 110(0 \%)$, Strand=Plus/Plus.

Figure (6): Sequencing of sense and antisense flanking the Fas gene for healthy as compared with standard Fas obtained 
from Gene Bank (A: Sense of the gene; B: Antisense of the gene).

Morever, we also found that Fas gene (flank DNA sense and antisense of the gene) ALL and CLL obtained from patients having $100 \%$ compatibility with standard Fas gene of Gene Bank as shown in figure (7).

\section{A: Sense of the partial Fas gene.}

Score $=204$ bits $(110)$, Expect $=2 e-50$, Identities $=110 / 110$ $(100 \%)$, Gaps $=0 / 110(0 \%)$, Strand $=$ Plus/Minus.

\section{Query 52 TTGGTGCAagggTCACAgTGTCACATACAgtagagTTACAaAaAagmTGgTTACAT 111

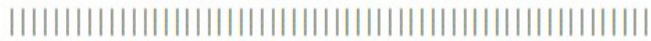 Sbjet 789 TTGGTGCAAGgGTCACAGTGTTCACATACAGTAGagTTACAAAAAAAGTTGGTTTACAT 730}

\section{Query 112 CIGCACTTGgTATTCTGGGICCGgGIGCAGTTTATTTCACTTCTAAGCC 161

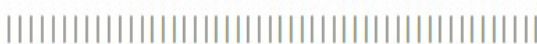 \\ Sbjct 729 CTGCACTTGgTATTCTGGgTCCGgGTGCAGTTTATTTCCACTTCTAAgCC 680}

\section{B: Antisense of the partial Fas gene.}

Score $=204$ bits $(110)$, Expect $=9 \mathrm{e}-52$, Identities $=110 / 110$ $(100 \%)$,

Gaps $=0 / 110(0 \%)$, Strand=Plus/Plus.

Figure (7): Sequencing of sense and antisense flanking the Fas gene (Exon4) for ALL and CLL as compared with standard Fas obtained from Gene Bank (A: Senses of the gene; B: Antisense of the gene).

Although the results did not detect any mutations in exon 4 of Fas gene, other investigators have detected a lack of 20 base pair at Exon 9 resulting in a frame shift mutation which resulting the generation of a pre mature stop codon at amino acid 239 of Acute T-cell leukemia (ATL) ( $22 \& 23)$, specify deletions in exon 9 in Fas gene, five missense mutations and one silent mutation in all 65 human non small cell lung cancers using PCR and DNA sequencing, they found that changes lead to loss of cells apoptotic functions and contribute to the pathogenesis of some human lung cancer. A novel Fas mutation which predicted the truncation of the intracytoplasmic domain of the Fas receptor in two siblings and the loss of Fas antigen expression by skipping of exon 4 of the Japanese patients (lymphoproliferative disorder) were detected (24) and Point mutation that was present in the splice acceptor site of intron 3 of the Fas gene were detected previously (18), this mutation results in the skipping of exon 4 and the complete loss of Fas expression.

\section{References}

Okur H.; Gunay B.; Nurten A.; Ahmet O.; Turkan P.; Ali S.; Sule U.; Aytemiz G. (2008).Clinical and molecular aspects of Turkish familial hemophagocytic lymphohistiocytosis patients with perforin mutations. Leukemia Research 32: 972-975.

Katano H. and Cohen JI. (2005). Perforin and lymphohistiocytic proliferative disorders. $\mathrm{Br} \mathrm{J}$ Haematol. 128:739-750.

Karapinar B.; Yilmaz D.; Aydinok Y.; Turkoglu E.; Hekimgil M. and Kavakli K.(2007). Intense myelofibrosis in a child: unusual result of EBV associated hemophagocytic lymphohistiocytosis. Turk J Hematol.24:32-5.
Henter JI.; Horne A.; Arico M.; Egeler RM.; Filipovich AH.; Imashuku S. (2007). HLH 2004,Diagnostic and therapeutic guidelines for hemophagocytic lymphohistiocytosis. Pediatr Blood Cancer.48:124-31.

5- Ericson KG.; Fadeel B.; Nilsson S.; Soderhall C.; Samuelsson A. and Janka G.(2001). Spectrum of perforin gene mutations in familial hemophgocytic lymphohistiocytosis. Am J.Hum Genet 68: 590-597.

6- Trambas C.; Gallo F.; Pende D.; Marcenaro S.; Moretta L.; De Fusco C. (2005) A single aminoacid change, A91V, leads to conformational changes that can impair processing to the active form of perforin. Blood.106:932-937.

7- Dufourcq R.; Jabado N.; Ledeist F.; Stephan J.; Souillet G.; Bruin M.; Vilmer E. (1999).Linkage of familial hemophagocytic lymphohistiocytosis to 10q2122 and evidence for heterogeneity.Am.J.Hum.Genet.64:172-179.

8- Voskoboinik I.; Thia MC. and Trapani JA. A (2005). Functional analysis of the putative polymorphisms A91V and $\mathrm{N} 252 \mathrm{~S}$ and 22 missense perforin mutations associated with familial hemophagocytic lymphohistiocytosis. Blood.105:4700-6.

9- Clementi R.; Emmi L. and Maccario R.(2002). Adult onset and atypical presentation of hemophagocytic lymphohistiocytosis in siblings carrying PRF1 mutations.Blood 100: 2266-2267.

10- Molleran L.; Villanueva J. and Sumega J.(2004). Characterisation of diverse PRF1 mutations leading to decreased natural killer cell activity in North American families with haemophagocytic lymphohistiocytosis J.Med.Gent. 41:137-144.

11- Marlise M. (1997). Chromosome sensitivity to bleomycin in G2 lymphocytes from Down's syndrome patients. Brazelian Journal of Genetics.1: 310-319.

12- Bottran R.F. and Vetvicka V. (2001). Advanced methods in cellular immunology. Boca Raton, New York, Washington,D.C.

13- Boyum, A (1968) Separation of lymphocyte from blood and bone marrow .Scand .J.clin .lab.invent .21.suppt .97.

14- Gen L.; Zheng-de X.; Kun-ling S.; Ling-jun Y.; Run-hui W.; Chun-yan L. (2009). Mutations in the perforin gene in children with hemophagocytic Lymphohistiocytosis. Chinese Medical Journal .122: 2851-2855.

15- Ueda I.; Kurokwa Y.; Koike K.; Ito S.; Sakata A.; Matsumora T. (2007). Late-onset cases of Familial hemophagocytic lymphohistiocytosis with missense perforin gene mutations. American journal of hematology. 82:427-432.

16- Muralitharan S.; Lamki Z.; Dennison D.; Christie B.; Wali Y.; Zachariah M.(2005). An inframe perforin gene deletion in familial hemophagocytic lymphohistiocytosis is associated with perforin expression. American Journal of hematology 78:59-63. 
17- Muralitharan S.; Wali Y.; Dennison D.; Lamki Z.; Zachariah M.; Nagwa E.(2007). Novel spectrum of perforin gene mutations in familial hemophagocytic lymphohistiocytosis in ethnic Omani patients. Am.J.Hematol. 82:1099-1102.

18- Yanai F.; Ishii E.; Kojima K.; Hasegawa A.; Azuma T.; Hirose S.; (2003). Essential roles of perforin in antigen specific cytotoxicity mediated by human CD4+ Tlymphocytes:analysis using the combination of hereditary perforin deficient effector cells and Fas-Deficient target cells. The Journal of Immunology, 170:2205-2213.

19- Maeda T.; Yamada Y.; Moriuchi R.; Sugahara K.; Tsuruda K.; Joh T. (1999). Fas gene mutation in the progression of adult T-cell leukemia . J.Exp. Med. 189: 10631071.

20- Risma KA.; Frayer RW.; Filipovich AH. And Surnegi J.(2006) .Aberrant maturation of mutant perforin underlies the clinical diversity of hemophagocytic lymphohistiocytosis. J.Clin Invest. 116: 182-192.

21- Mancebo E.; Allende L.; Guzman M.; Paz-Artal E.; Gil J.(2006). Familial hemophagocytic lymphohistiocytosis in an adult patient homozygous for $\mathrm{A} 91 \mathrm{~V}$ in the perforin gene, with tuberculosis infection. Haematologica 91:1257-1260.

22- Mehta PA.; Davies SM.; Kumar A.; Devidas M.; Lee S.; Zamzow T.; Elliott J.; Villanueva J.; Pullen J. and Zewge Y. (2006). Perforin polymorphism A91V and susceptibility to Bprecursor childhood acute lymphoblastic leukemia: a report from the Children's Oncology Group. Leukemia. 20:1539 1541.

23- Lee S.; Shin M.; Park W.; Kim S.; Kim H.; Han J. (1999). Alterations of Fas gene in non-small cell lung cancer. Oncogene 18: 3754-3760.

24- Kasahara Y.; Wada T.; Niida Y.; Yachie A.; Seki H.; Ishida Y. (1997). Novel Fas mutation in infants with a lymphoproliferative disorder. International Immunology.10: 195-202.

http://www.ncbi.nlm.nih.gov/books/bv.fcgi?call=bv.View..Sh owTOC\&rid=imm. TOC\&depth $=10$. 